Proceedings of the Edinburgh Mathematical Society (2014) 57, 573-574

DOI:10.1017/S0013091514000029

\title{
OBITUARY
}

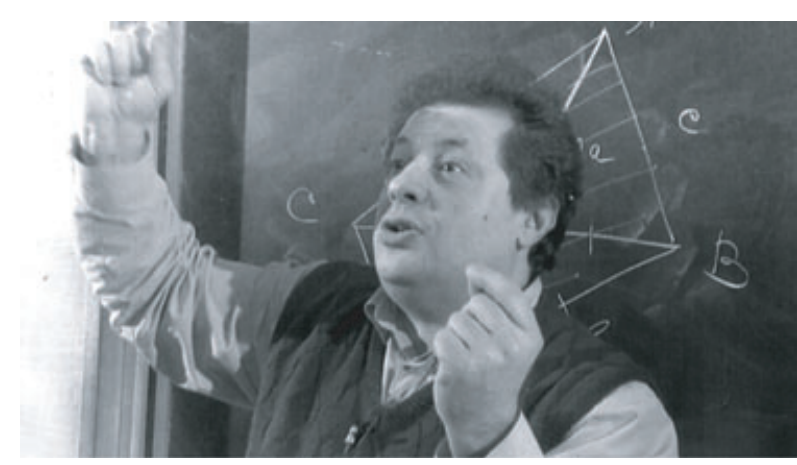

\section{Vitali Liskevich}

\author{
Born: 26 April 1956 \\ Died: 27 September 2012
}

Vitali Liskevich was born on 26 April 1956 in Kiev, Ukraine. He was first educated as an electronic engineer at Kiev Polytechnic Institute, before studying mathematics at Kiev State University in 1979-85. He received his $\mathrm{PhD}$ in mathematics from the Institute of Mathematics of the Ukrainian Academy of Science in Kiev in 1990, under the supervision of Yuliy Semenov and Yurij Berezanskii. Shortly afterwards, Vitali and his family moved to Israel, where he took a postdoctoral position at the prestigious Weizmann Institute of Science, and later at the Hebrew University of Jerusalem. In 1995 Vitali was awarded the Alexander von Humboldt Foundation fellowship, which he spent working at the Technical University of Dresden. In 1996 he was appointed a lecturer at the University of Bristol. Soon after he was promoted to reader and, in 2003, to professor. In 2007 he moved to Swansea University, where he was a professor until his untimely death on 27 September 2012.

Vitali's main research interests were in the areas of semigroup theory, spectral theory and linear and nonlinear partial differential equations. He made a number of significant contributions to such topics as heat kernel estimates for Schrödinger operators, uniqueness and spectral independence for Dirichlet operators, nonlinear Liouville-type theorems, Harnack-type inequalities and regularity of solutions of linear and quasilinear elliptic and parabolic equations. A distinctive feature of his mathematical results was always precision: in the choice of function classes he used, and even in the values of constants in the estimates obtained. The problems that he worked on were quite diverse. Looking at them, one gets an impression that he was in a hurry, as if he felt that he did not have much time, although symptoms of a fatal illness appeared relatively late. Vitali published more than 60 research papers and was active in research until his very last days. He served on the editorial board of the Proceedings of the Edinburgh Mathematical Society between 2006 and 2011.

In addition to his research achievements, Vitali was an engaging and charismatic lecturer. His passion and enthusiasm for mathematics will be remembered by all who knew him. He showed 
enormous courage in the face of a daunting illness: courage that even extended to giving a lecture on Hilbert's Hotel to his fellow patients and some of the staff in the hospital ward where he was being treated just a few days before he died. He was a prominent member of the international mathematical community, eager to share his love of mathematics, and he is thoroughly missed by his colleagues and friends.

Vitali is survived by his loving wife Yelena and two sons, Alexander and David.

Vitaly Moroz, Swansea University Michael Solomyak, Weizmann Institute of Science Aubrey Truman, Swansea University 
https://doi.org/10.1017/S0013091514000029 Published online by Cambridge University Press 
https://doi.org/10.1017/S0013091514000029 Published online by Cambridge University Press 